\title{
Regulation of the Concentration of Adenosine 3',5'-Cyclic Monophosphate and the Activity of Tyrosine Hydroxylase in the Rat Superior Cervical Ganglion by Three Neuropeptides of the Secretin Family ${ }^{1}$
}

\author{
N. Y. IP, ${ }^{2}$ C. BALDWIN, AND R. E. ZIGMOND \\ Department of Pharmacology, Harvard Medical School, Boston, Massachusetts 02115
}

\begin{abstract}
Preganglionic nerve stimulation leads to an acute elevation of tyrosine hydroxylase (TH) activity in the rat superior cervical ganglion. This effect is mediated in part by acetylcholine, acting via nicotinic receptors, and in part by a noncholinergic neurotransmitter. As a first step in an attempt to identify this noncholinergic transmitter, we have examined a number of biogenic amines, purine nucleotides, neuropeptides, and other compounds for their ability to increase TH activity. Secretin, vasoactive intestinal peptide (VIP), and PHI (a 27-amino acid peptide with an $\mathrm{NH}_{2}$-terminal histidine and a COOH-terminal isoleucine amide), all members of the secretin family of peptides, increased TH activity acutely. Human pancreatic growth hormone-releasing factor, glucagon, and gastric inhibitory peptide (three other members of this peptide family) and all other transmitter candidates tested had no effect on this enzyme activity.

We have examined the possibility that this peptidergic regulation of TH activity is mediated via changes in adenosine $3^{\prime}, 5^{\prime}$-cyclic monophosphate (cAMP) levels. When the six members of the secretin family were tested for their ability to increase CAMP levels in the ganglion, secretin, VIP, and PHI significantly increased this cyclic nucleotide, whereas growth hormone-releasing factor, glucagon, and gastric inhibitory peptide produced no significant effects. The rank orders of potency and of efficacy of secretin, VIP, and $\mathrm{PHI}$ in altering TH activity and CAMP levels were identical. Furthermore, a strong correlation was found between the CAMP level and the TH activity in individual ganglia exposed to these peptides. Finally, 8-bromoadenosine $3^{\prime}, 5^{\prime}$-cyclic monophosphate and forskolin also increased TH activity. We hypothesize that CAMP is the second messenger mediating
\end{abstract}

Received July 26, 1984; Revised December 10, 1984:

Accepted December 11, 1984

1 We would like to thank Dr. James Nathanson and Mr. Ed Hunnicut for their help in setting up the cAMP assay and for their generous gift of CAMP binding protein. We would also like to thank Drs. Alice Liu, Michael Goy, Jonathan Smith, and Keith Miller for many helpful discussions. This work was supported by United States Public Health Service Grant NS12651. N. Y. I. was supported by National Institutes of Health Postdoctoral Training Grant NS07009, and R. E. Z. was supported by National Institute of Mental Health Research Scientist Development Award MH00162.

${ }^{2}$ Present address: Laboratory of Cellular Gene Expression and Regulation, Sloan-Kettering Institute for Cancer Research, 1275 York Avenue, New York, NY 10021.

${ }^{3}$ To whom correspondence should be addressed. the increase in TH activity produced by these peptides. The nicotinic agonist dimethylphenylpiperazinium also increased TH activity but did not alter CAMP levels. In contrast, the ability of this nicotinic agonist to increase TH activity, but not that of secretin or VIP, was highly dependent on the calcium concentration of the medium. Since nicotinic stimulation is known to increase calcium entry into ganglion cells, we hypothesize that calcium is the second messenger mediating the increase in TH activity produced by nicotinic agonists.

These results indicate that secretin, VIP, PHI, or a related peptide may play an important role in regulating catecholamine synthesis in sympathetic neurons and perhaps in regulating other cAMP-dependent processes. The data also suggest that $\mathrm{TH}$ activity in sympathetic ganglia is acutely regulated by more than one intracellular mechanism.

In the past decade, the number of "putative" neurotransmitters under investigation has increased more than 3-fold. This increase is due almost entirely to the discovery of a large number of biologically active peptides in the central and peripheral nervous systems (Krieger et al., 1983). In many cases, the only evidence that these peptides may play an important role in the nervous system is that they are concentrated in specific parts of the central and/or peripheral nervous system. Little is known about the function of specific peptides in these systems.

Among the most extensive investigations of peptides as neurotransmitters are studies in sympathetic ganglia. Due to the relative simplicity of the anatomy and pharmacology of these neural structures, they are highly suitable for such investigations. A peptide which resembles, although it probably is not identical to, luteinizing hormone-releasing hormone has been shown to be released by preganglionic neurons in the 9th and 10th paravertebral ganglia of the frog (Jan and Jan, 1982). Histochemical studies indicate that this peptide is likely to be released by the same preganglionic neurons which release acetylcholinc. Substance $P$ has been shown to be released in the inferior mesenteric ganglion of the guinea pig by neurons having cell bodies located in dorsal root ganglia (Dun and Jiang, 1982; Tsunoo et al., 1982). In the cases just cited, the peptides produce long-lasting depolarizations in the neurons on which they act. However, the functional significance of these slow changes in membrane potential remains to be determined. It is possible, for example, that in certain cases the most important effect of transmitters which produce relatively small depolarizations on a slow (second to minute) time scale may be biochemical rather than electrophysiological in nature.

We have recently found that two neuropeptides, secretin and vasoactive intestinal peptide (VIP), can produce an acute increase in the activity of tyrosine 3-monooxygenase (tyrosine hydroxylase 
TABLE I

Effects of various biogenic amines, purine nucleotides, and other compounds on $\mathrm{TH}$ activity in the superior cervical ganglion

Ganglia were preincubated for $30 \mathrm{~min}$ with control medium and then incubated for $30 \mathrm{~min}$ with brocresine $(150 \mu \mathrm{M})$ and with the compounds listed below at the concentrations indicated. The amount of dopa accumulated during the incubation period was determined. The rate of dopa synthesis is expressed as a percentage of the rate found in ganglia incubated in the presence of medium containing brocresine alone (mean \pm SEM). The average rate of dopa synthesis under these control conditions was $37 \pm 2$ pmol/ganglion/30 min. Each value represents the mean of three to four ganglia. In the experiments with dopamine, norepinephrine, and isoprotereno (except the second experiment with $10 \mu \mathrm{M}$ isoproterenol), desmethylimipramine $\left(10^{-5} \mathrm{M}\right)$ was added to block catecholamine uptake.

\begin{tabular}{|c|c|}
\hline Compound & $\begin{array}{c}\text { Lopa Synthesis } \\
\text { (\% control) }\end{array}$ \\
\hline \multicolumn{2}{|l|}{ Dopamine } \\
\hline$(1 \mu \mathrm{M})$ & $88 \pm 7$ \\
\hline$(10 \mu \mathrm{M})$ & $90 \pm 4$ \\
\hline \multicolumn{2}{|l|}{ Norepinephrine } \\
\hline$(1 \mu \mathrm{M})$ & $79 \pm 4$ \\
\hline$(10 \mu \mathrm{M})$ & $101 \pm 6$ \\
\hline \multicolumn{2}{|l|}{ Isoproterenol } \\
\hline$(1 \mu \mathrm{M})$ & $106 \pm 15$ \\
\hline$(10 \mu \mathrm{M})$ & $101 \pm 4$ \\
\hline$(10 \mu \mathrm{M})^{\mathrm{a}}$ & $122 \pm 7$ \\
\hline \multicolumn{2}{|l|}{ Serotonin } \\
\hline$(10 \mu \mathrm{M})$ & $93 \pm 5$ \\
\hline \multicolumn{2}{|l|}{ Histamine } \\
\hline$(10 \mu \mathrm{M})$ & $99 \pm 9$ \\
\hline \multicolumn{2}{|l|}{ Adenosine } \\
\hline$(500 \mu \mathrm{M})$ & $92 \pm 1$ \\
\hline \multicolumn{2}{|l|}{ Chloroadenosine } \\
\hline$(100 \mu \mathrm{M})$ & $93 \pm 10$ \\
\hline \multicolumn{2}{|l|}{ Adenosine triphosphate } \\
\hline$(100 \mu \mathrm{M})$ & $78 \pm 8$ \\
\hline \multicolumn{2}{|l|}{ Prostaglandin $E_{1}$} \\
\hline$(30 \mathrm{nM})$ & $108 \pm 6$ \\
\hline
\end{tabular}

${ }^{a}$ Without desmethylimipramine $\left(10^{-5} \mathrm{M}\right)$.

$(\mathrm{TH})$; EC 1.14.16.2) in the rat superior cervical ganglion (Ip et al., 1982a). This enzyme catalyzes the rate-limiting step in catecholamine biosynthesis and has been shown to be controlled by a variety of regulatory mechanisms (Weiner et al., 1977; Zigmond, 1980). For example, in the rat superior cervical ganglion, increased preganglionic nerve activity leads to a delayed and long-lasting increase in TH activity (Zigmond and Ben-Ari, 1977; Chalazonitis et al., 1980) and also to a rapid and probably short-fived increase in enzyme activity (Ip et al., 1982b, 1983). Whereas the former transsynaptic effect of nerve stimulation can be entirely blocked by nicotinic antagonists (Chalazonitis et al., 1980; Chalazonitis and Zigmond, 1980), the latter effect can be blocked only partially by such agents (Ip et al., 1983). Based on the fact that an acute elevation of $\mathrm{TH}$ activity is seen in the presence of high concentrations of both nicotinic and muscarinic antagonists, we have concluded that there is a noncholinergic transmitter involved in this process, possibly a neuropeptide (ip et al., 1982a, 1983).

In the present study we have tested the ability of a number of biogenic amines, purine nucleotides, peptides, and other compounds to mimic the noncholinergic regulation of $\mathrm{TH}$. Of all the transmitter candidates examined, only secretin, VIP, and PHI (a 27 amino acid peptide with an $\mathrm{NH}_{2}$-terminal histidine and a $\mathrm{COOH}$ terminal isoleucine amide) increased $\mathrm{TH}$ activity. We have also examined the mechanism by which these three peptides produce this effect. Preliminary reports of these results have been presented at the Conference on VIP and Related Peptides (ip et al., 1984) and at the Society for Neuroscience (lp and Zigmond, 1983; Zigmond et al., 1983).
TABLE \|

The effect of various peptides on $T H$ activity and CAMP content in the superior cervical ganglion

In most cases dopa synthesis was measured during a 30-min incubation with one of the peptides $(10 \mu \mathrm{M})$ and brocresine. In the case of human pancreatic growth hormone-releasing hormone (hpGRF; $10 \mu \mathrm{M}$ ) and avian pancreatic polypeptide $(5 \mu \mathrm{M})$ ganglia were preincubated with the peptides for $60 \mathrm{~min}$, and then brocresine was added and the incubation continued for $15 \mathrm{~min}$. For each peptide, the rate of dopa synthesis was compared to that in ganglia incubated under comparable conditions but with no peptide included in the medium. The mean control rate of dopa synthesis was $45 \pm$ $3 \mathrm{pmol} / \mathrm{ganglion} / 30 \mathrm{~min}$. Each value represents the mean \pm SEM of three to five ganglia except glucagon $(n=8), \mathrm{VIP}(n=12)$, and secretin $(n=12)$.

CAMP content was measured after a 10-min incubation with each of the peptides $(10 \mu \mathrm{M})$ except in experiments with gastric inhibitory peptide, cholecystokinin octapeptide, and motilin, in which a 30-min incubation was used. The data represent the means \pm SEM of four ganglia except for VIP $(n=36)$ and secretin $(n=26)$. The mean control cAMP content was $1.2 \pm$ $0.1 \mathrm{pmol} /$ ganglion.

\begin{tabular}{|c|c|c|}
\hline Peptide & $\begin{array}{c}\text { Dopa Synthesis } \\
\text { (\% control) }\end{array}$ & $\begin{array}{l}\text { CAMP Content } \\
(\% \text { control) }\end{array}$ \\
\hline \multicolumn{3}{|l|}{ Secretin family } \\
\hline VIP & $450 \pm 29^{a}$ & $724 \pm 44^{a}$ \\
\hline Secretin & $328 \pm 17^{a}$ & $357 \pm 13^{a}$ \\
\hline $\mathrm{PHI}$ & $191 \pm 11^{\mathrm{a}}$ & $258 \pm 42^{\circ}$ \\
\hline hpGRF & $102 \pm 6$ & $84 \pm 10$ \\
\hline Glucagon & $93 \pm 4$ & $99 \pm 23$ \\
\hline Gastric inhibitory peptide & $87 \pm 5$ & $69 \pm 9$ \\
\hline \multicolumn{3}{|l|}{ Other peptides } \\
\hline Neuropeptide $Y$ & $90 \pm 8$ & $N D^{c}$ \\
\hline Avian pancreatic polypeptide & $96 \pm 13$ & ND \\
\hline$\left[\right.$ Arg $\left.^{8}\right]$ Vasopressin & $120 \pm 8$ & ND \\
\hline
\end{tabular}

a Significantly greater than control ganglia $(p<0.001)$.

${ }^{b}$ Significantly greater than control ganglia $(p<0.025)$.

${ }^{c} \mathrm{ND}$, not determined.

\section{Materials and Methods}

Male Sprague-Dawley rats (100 to $125 \mathrm{gm}$ at the time of shipment from Charles River Breeding Laboratories, Wilmington, MA) were housed for about a week in individual plastic cages under controlled lighting (12 hr light:12 h dark) with ad libitum access to Purina Rat Chow and water. The rats were killed by cervical dislocation, and the superior cervical ganglia were removed and desheathed.

Measurement of TH activity. TH activity was assessed by measuring the rate of dopa accumulation in the presence of a dopa decarboxylase inhibitor (Ip et al., 1982b). Individual ganglia were preincubated at $37^{\circ} \mathrm{C}$ for $30 \mathrm{~min}$ in Earle's balanced salt solution (Grand Island Biological Co., Grand Island, NY) supplemented with $0.1 \mathrm{~mm}$ tyrosine and $0.1 \mathrm{mM}$ EDTA and equilibrated with $95 \% \mathrm{O}_{2} / 5 \% \mathrm{CO}_{2}$, except where noted. Ganglia were then transferred to a second beaker and incubated for $30 \mathrm{~min}$ in medium containing the compound to be studied and brocresine $(150 \mu \mathrm{M})$, an inhibitor of dopa decarboxylase (aromatic I-amino acid decarboxylase; EC 4.1.1.28). In certain of the experiments in which the effects of neuropeptides were examined, the ganglia were preincubated in medium containing the peptide for $60 \mathrm{~min}$, and then brocresine was added and the ganglia were incubated for another $15 \mathrm{~min}$. In one experiment in which the effects of altering the ionic composition of the medium were examined, ganglia were incubated in either Earle's balanced salt solution (which contains $1.8 \mathrm{~mm}$ calcium and $0.8 \mathrm{~mm}$ magnesium) or in medium containing a low concentration of calcium $(0.1 \mathrm{~mm})$ and a high concentration of magnesium $(2.5 \mathrm{~mm})$ during both the preincubation and the incubation periods. In all experiments, the ganglia were homogenized in 1.65 $M$ trichloroacetic acid/1 mM EDTA at the end of the incubation period. The homogenates were then combined with their respective incubation media and centrifuged, and the dopa content of the supernatant fractions was determined by high performance liquid chromatography using electrochemical detection, as previously described (lp et al., 1982b). The significance of differences between groups was assessed by the Student's $t$ test for two means, two-tailed.

Measurement of CAMP. When both dopa and CAMP were measured in the same sample, an aliquot of the supernatant was extracted five times with 


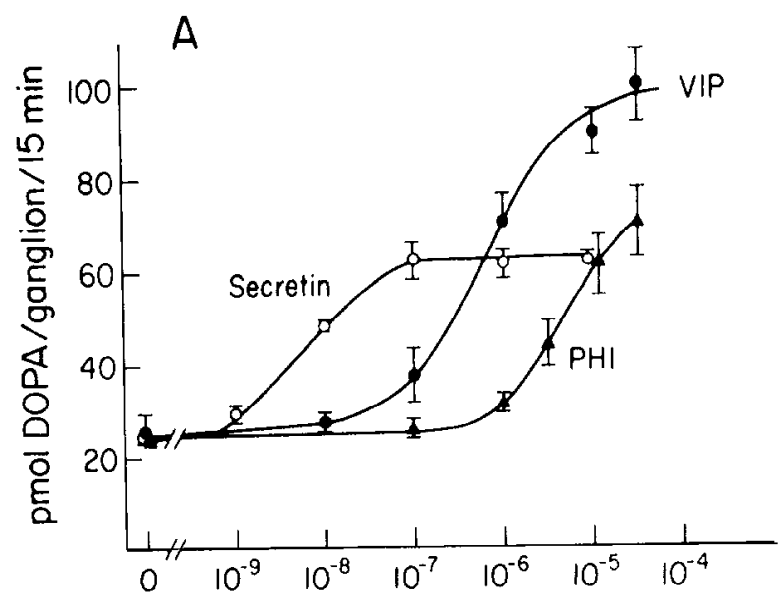

TABLE III

tffect of secretin and VIP on the CAMP content of the superior cervical ganglion in the absence and presence of theophylline

Ganglia were preincubated in control medium for $30 \mathrm{~min}$ and then incubated with the compounds indicated for $30 \mathrm{~min}$. The CAMP values given represent the mean \pm SEM of four ganglia.

\begin{tabular}{lc}
\hline Additions & $\begin{array}{c}\text { cAMP Content } \\
\text { (pmol of CAMP/ganglion) }\end{array}$ \\
\hline None & $1.2 \pm 0.1$ \\
Theophylline $(10 \mathrm{mM})$ & $2.6 \pm 0.3$ \\
Secretin $(10 \mu \mathrm{M})$ & $4.8 \pm 0.6$ \\
Theophylline + secretin & $18.6 \pm 2.0$ \\
None & $0.8 \pm 0.1$ \\
Theophylline & $2.3 \pm 0.4$ \\
VIP $(10 \mu \mathrm{M})$ & $6.7 \pm 1.1$ \\
Theophylline + VIP & $26.2 \pm 2.9$ \\
\hline
\end{tabular}

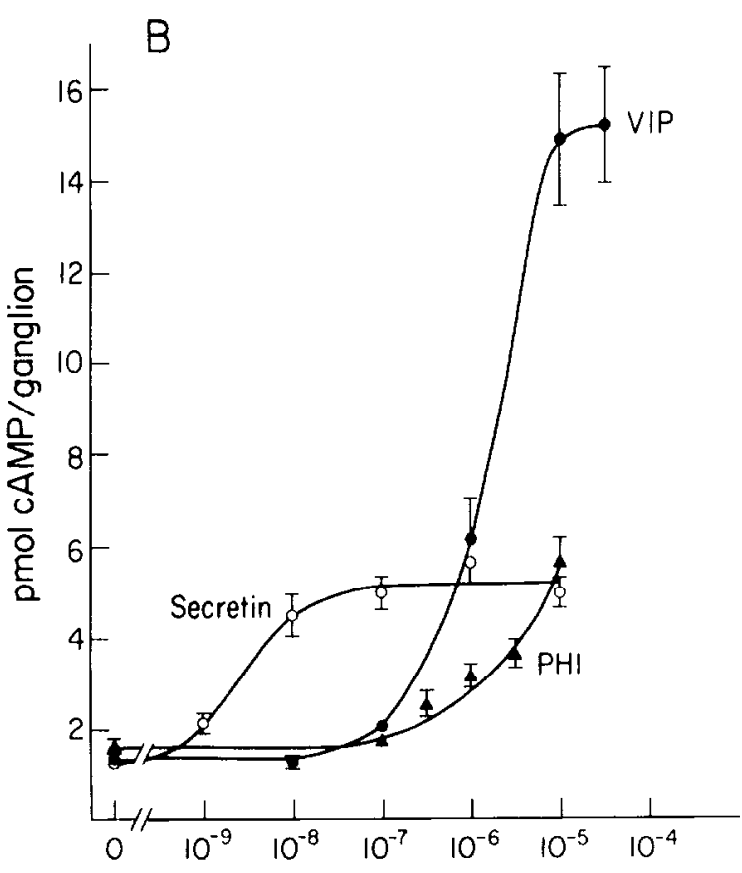

[Peptide] (M)

Figure 1. Dose-response curves for the effects of secretin, VIP, and PHI on TH activity and on the CAMP content of the superior cervical ganglion. Ganglia were preincubated for $60 \mathrm{~min}$ with one of the peptides. Brocresine was then added, and the incubation was continued for an additional $15 \mathrm{~min}$. $A$. The effects of various concentrations of $\mathrm{PHI}$ (from $10^{-7} \mathrm{M}$ to $3 \times 10^{-5} \mathrm{M}$ ) on $\mathrm{TH}$ activity were examined; the results are compared to previously published data for secretin and VIP (Ip et al., 1982a). The data for PHI represent the mean \pm SEM of four ganglia. $B$, In separate experiments, using identical incubation condilions, the CAMP content of ganglia was determined. Each point represents the mean \pm SEM of three to four ganglia for VIP and $\mathrm{PHI}$ and 11 ganglia for secretin.

5 vol of water-saturated diethyl ether. The samples were then dried down in a Speed-Vac centrifuge (Savant, Hicksville, NY). The pellets were resuspended in water and assayed for CAMP by the competitive protein binding assay of Brown et al. (1971) using $\left.{ }^{3} \mathrm{H}\right] \mathrm{CAMP}$ (32 Ci/mmol; New England Nuclear Corp., Boston, MA). In experiments in which only CAMP was to be measured, ganglia were preincubated with control medium for at least 30 $\mathrm{min}$ and then were incubated for 10 or $30 \mathrm{~min}$ with an agonist. The incubation was terminated by boiling the ganglia and media for? $\mathrm{min}$. The ganglia were then homogenized in their incubation media, the samples were centrifuged, and the supernatants were stored at $-20^{\circ} \mathrm{C}$ until they were assayed. Three types of control experiments were done to determine to what extent the material in the ganglion homogenates that was detected by the protein binding assay was authentic CAMP. Dilution of samples produced a proportional reduction in the amount of CAMP measured. Addition of authentic CAMP to samples produced the appropriate increment in CAMP detected.

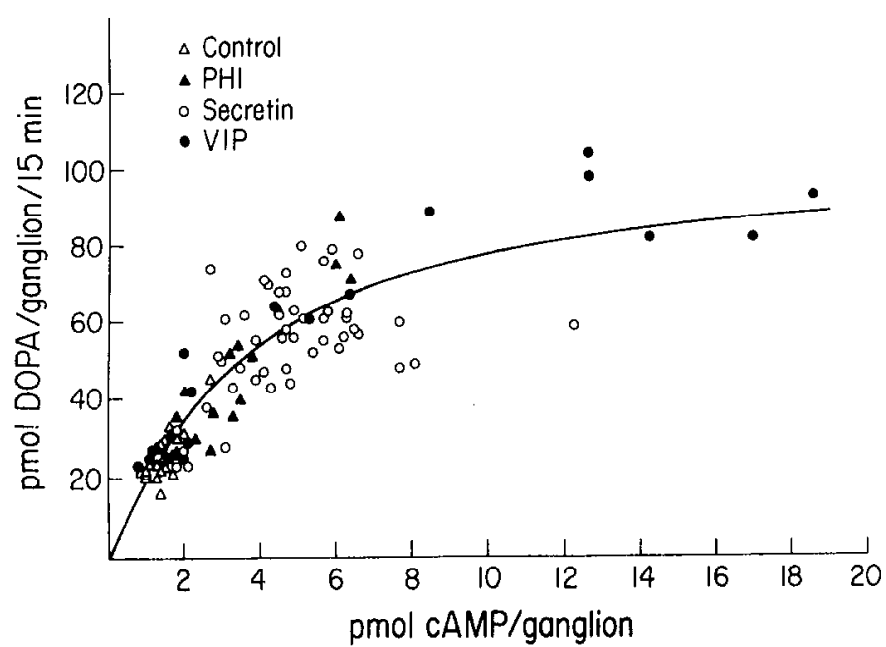

Figure 2. Comparison of the effects of secretin, VIP and $\mathrm{PHI}$ on the rate of dopa synthesis and on the CAMP content of the superior cervical ganglion. Most of the data are taken from the experiment presented in Figure $1 B$. Each data point represents a single ganglion. The data were fitted to the Hill equation by a nonlinear least squares method. The Hill coefficient was 1.1 \pm 0.17 (mean $\pm \mathrm{SD}$ ), and the cAMP concentration at which TH activity reached its half-maximal value was $3.7 \pm 0.9 \mathrm{pmol} / \mathrm{gang} g$ lion. The maximal value for TH activity was $103 \pm 13 \mathrm{pmol}$ of dopa/ganglion/15 min.

Finally, preincubation of samples for $15 \mathrm{~min}$ at $30^{\circ} \mathrm{C}$ with phosphodiesterase $3^{\prime}, 5^{\prime}$-cyclic nucleotide $(200 \mu \mathrm{g} / \mathrm{ml}$, crude complex; Sigma Chemical Co., St. Louis, MO) in $40 \mathrm{~mm}$ Tris buffer ( $\mathrm{pH} 8.0$ ) containing $10 \mathrm{~mm} \mathrm{MgCl}_{2}$ abolished any detectable CAMP in the samples.

Materials. Adenosine, adenosine $5^{\prime}$-triphosphate, 8-bromoadenosine, 8 . bromoadenosine $5^{\prime}$-rioriophusphale, 8-bromoadenosine $3^{\prime}, 5^{\prime}$-cyclic monophosphate (8-bromo-cAMP), 8-bromoguanosine $3^{\prime}, 5^{\prime}$-cyclic monophosphate, chloroadenosine, 1,1-dimethylphenylpiperazinium iodide, dopamine, gastric inhibitory peptide, glucagon (purified from pancreas), histamine, 1 isoproterenol, motilin, /-norepinephrine, prostaglandin $E_{1}$, serotonin, and theophylline were obtained from Sigma Chemical Co. Angiotensin II. $\left[\mathrm{Arg}^{8}\right]$ vasopressin, avian pancreatic peptide, bradykinin, human pancreatic tumor growth hormone-releasing factor, neuropeptide $Y$, neurotensin, secretin, substance $P$, and VIP were purchased from Peninsula Laboratories (Belmont, CA). PHI was obtained from Bachem (Torrance, CA), cholecystokinin octapeptide was from Beckman Instruments (Palo Alto, CA), forskolin was from Calbiochom (La Jolla, CA), and dimethylsulfoxide was from Fisher (Pittsburgh, PA). Brocresine was a gift from Dr. David N. Ridge, Lederle Laboratory (Pearl River, NY); desmethylimipramine was obtained from USV Pharmaceutical Curp., (Tuckahoe, NY); synthetic glucagon was a gift from Dr. thenry Keutmann; and Ro 20-1724 was a gift from Dr. W. E. Scott, Hoffmann-La Roche, Inc., (Nutley, NJ).

\section{Results}

Effects of various putative transmitters on ganglionic TH activity. As part of an attempt to determine the identity of the transmitter 


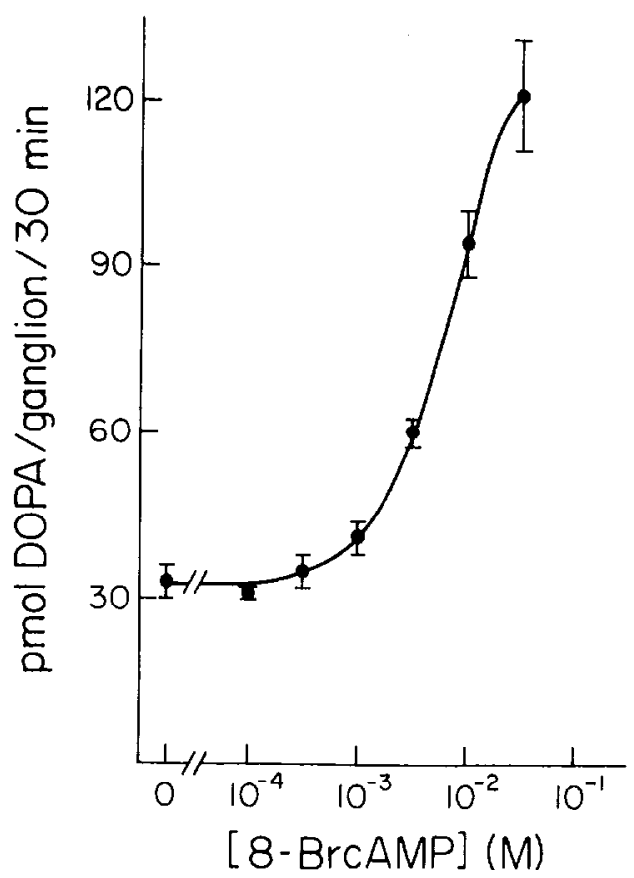

Figure 3. Dose-response curve of the effect of 8-bromo-cAMP (8-BrcAMP) on ganglionic TH activity. Ganglia were preincubated for $30 \mathrm{~min}$ in control medium and then incubated with brocresine and various concentrations of 8-bromo-cAMP for $30 \mathrm{~min}$. Each data point represents the mean \pm SEM of three to four ganglia.

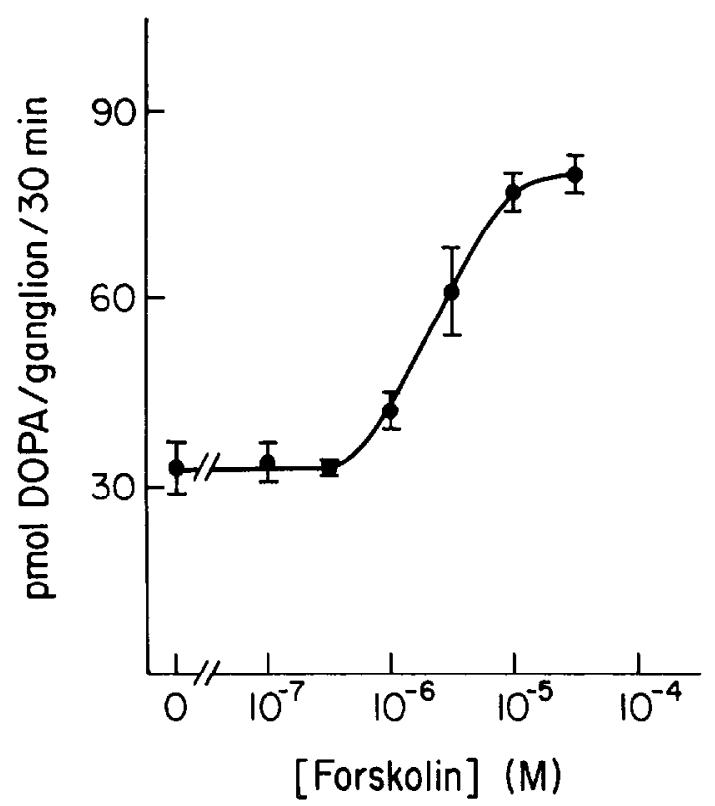

Figure 4. Dose-response curve for the effect of forskolin on TH activity in the superior cervical ganglion. Ganglia were preincubated for $30 \mathrm{~min}$ and then incubated with brocresine and various concentrations of forskolin for $30 \mathrm{~min}$. Each point represents the mean \pm SEM of three or four ganglia.

responsible for the noncholinergically mediated, trans-synaptic elevation of ganglionic $\mathrm{TH}$ activity, we examined the ability of a large number of transmitters, putative transmitters, and analogues of these molecules to mimic this increase in $\mathrm{TH}$ activity. Dopamine, norepinephrine, isoproterenol, serotonin, histamine, adenosine, chloroadenosine, adenosine triphosphate, and prostaglandin $E_{1}$ had no significant effects on the rate of dopa synthesis in the superior cervical ganglion at the concentrations examined (Table I). Since we had previously found that secretin and VIP, two members of the secretin family of peptides, could increase TH activity (lp et al.,
TABLE IV

Potentiation by fo 20-1724 of the increase in TH activity produced by forskolin

Ganglia were preincubated for $30 \mathrm{~min}$ with control medium and then incubated with brocresine together with forskolin $(10 \mu \mathrm{M})$ in the absence or presence of Ro $20-1724$ (100 $\mu \mathrm{M}$ in $0.5 \%$ dimethylsulfoxide (DMSO). The data are the means \pm SEM of four ganglia.

\begin{tabular}{lc}
\multicolumn{1}{c}{ Additions } & $\begin{array}{c}\text { Dopa Synthesis } \\
\text { (pmol/ganglion/30 min) }\end{array}$ \\
\hline None & $36 \pm 1^{\mathrm{a}}$ \\
DMSO alone & $35 \pm 2$ \\
Ro 20-1724 & $35 \pm 3$ \\
Forskolin & $63 \pm 3^{\mathrm{a}, b}$ \\
Forskotin + Ro 20-1724 & $94 \pm 4^{b}$ \\
\hline
\end{tabular}

${ }^{\text {a }}$ Significantly different $(\rho<0.001)$.

${ }^{b}$ Significantly different $(\rho<0.005)$.

\section{TABLE $V$}

Effect of 8-bromo-CAMP on TH activity in decentralized ganglia

Rats were anesthetized with chloral hydrate $(700 \mathrm{mg} / \mathrm{kg}$. s.C.) and were either sham-operated or had their cervical sympathetic trunks cut bilaterally. Four days later, the superior cervical ganglia were removed, preincubated for $30 \mathrm{~min}$ with control medium, and then incubated for $30 \mathrm{~min}$ with brocresine alone or brocresine plus 8-bromo-cAMP $(10 \mathrm{~mm})$. The data represent the means \pm SEM of four ganglia. No significant differences were seen between control and decentralized ganglia for either of the two incubation conditions.

\begin{tabular}{ccc}
\hline \multirow{2}{*}{ Treatment } & \multicolumn{2}{c}{$\begin{array}{c}\text { Dopa Synthesis } \\
\text { (pmol/ganglion/30 min) }\end{array}$} \\
\cline { 2 - 3 } & Control & 8-bromo-cAMP \\
\hline Sham-operated & $41 \pm 2$ & $109 \pm 13$ \\
Decentralized & $38 \pm 5$ & $88 \pm 11$ \\
\hline
\end{tabular}

1982a), we examined the effects of four other members of this family. PHI $(10 \mu \mathrm{M})$ caused approximately a doubling in $\mathrm{TH}$ activity, whereas human pancreatic tumor growth hormone-releasing factor, glucagon, and gastric inhibitory peptide produced no significant effects at the same concentration (Table II, column 2). Three other peptides structurally unrelated to secretin-neuropeptide $Y$, avian pancreatic peptide, and $\left[\mathrm{Arg}^{8}\right]$ vasopressin-also did not alter $\mathrm{TH}$ activity (Table II).

The dose-response relationship for the effect of $\mathrm{PHI}$ on dopa synthesis was examined, and the data were compared to those previously reported for secretin and VIP (Ip et al., 1982a). PHI was at least three orders of magnitude less potent than secretin and one order of magnitude less potent than VIP (Fig. 1A). However, as concentrations of $\mathrm{PHI}$ above $30 \mu \mathrm{M}$ were not examined, the maximum effect of this peptide and thus its $\mathrm{EC}_{50}$ remain undetermined.

Involvement of CAMP in TH regulation. The physiological effects of secrotin and VIP in a number of tissues are thought to be mediated via increases in the intracellular concentration of CAMP (Gardner and Jensen, 1981; Amiranoff and Rosselin, 1982). We therefore tested the ability of the six members of the secretin family to increase CAMP levels in the rat superior cervical ganglion. VIP, secretin, and $\mathrm{PHI}$ at a concentration of $10 \mu \mathrm{M}$ significantly increased the levels of this cyclic nucleotide, whereas human pancreatic growth hormonereleasing factor, glucagon, and gastric inhibitory peptide had no significant effects (Table $\|$, column 3 ). In addition, a number of other peptides which do not affect $\mathrm{TH}$ activity (Ip et al., 1982a) were examined for their ability to alter cAMP levels, namely, angiotensin II, bradykinin, cholecystokinin octapeptide, motilin, neurotensin, and substance $P$. None of these peptides affected cAMP levels at a concentration of $10 \mu \mathrm{M}$ (data not shown). The effects of secretin and VIP $(10 \mu \mathrm{M})$ on the CAMP content of the superior cervical ganglion were examined in the presence and absence of the phosphodiesterase inhibitor theophylline. Both peptides increased CAMP levels under both conditions, although larger-percentage increases were seen in the presence of theophylline (Table III). 

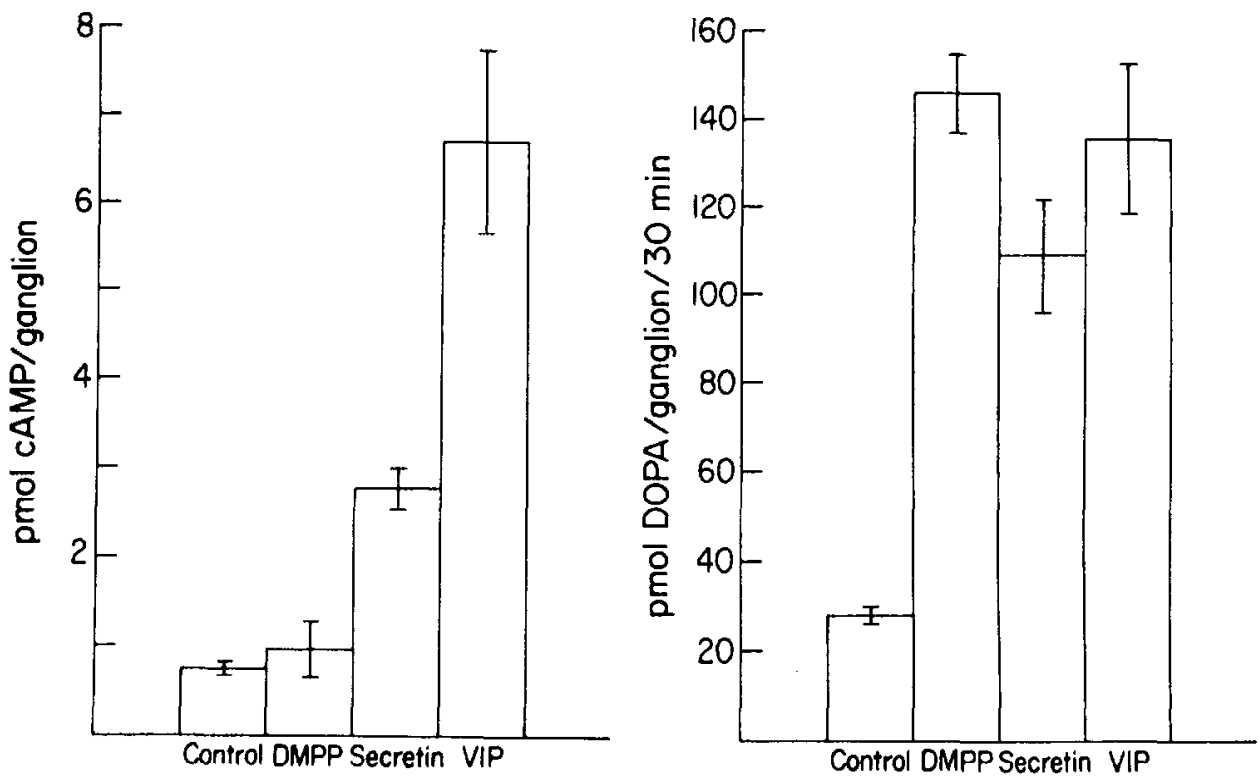

Figure 5. Effects of dimethylphenylpiperazinium (DMPP), secretin, and VIP on the CAMP concentration and the rate of dopa synthesis in the superior cervical ganglion. Ganglia were preincubated for $30 \mathrm{~min}$ in control medium and then incubated for 30 $\mathrm{min}$ in medium containing brocresine alone or brocresine plus either DMPP $(100 \mu \mathrm{M})$, secretin $(10 \mu \mathrm{M})$, or VIP $(10 \mu \mathrm{M})$. At the end of the incubation period, the CAMP and dopa contents of the ganglia plus media were determined. Each group represents the mean \pm SEM of four ganglia.

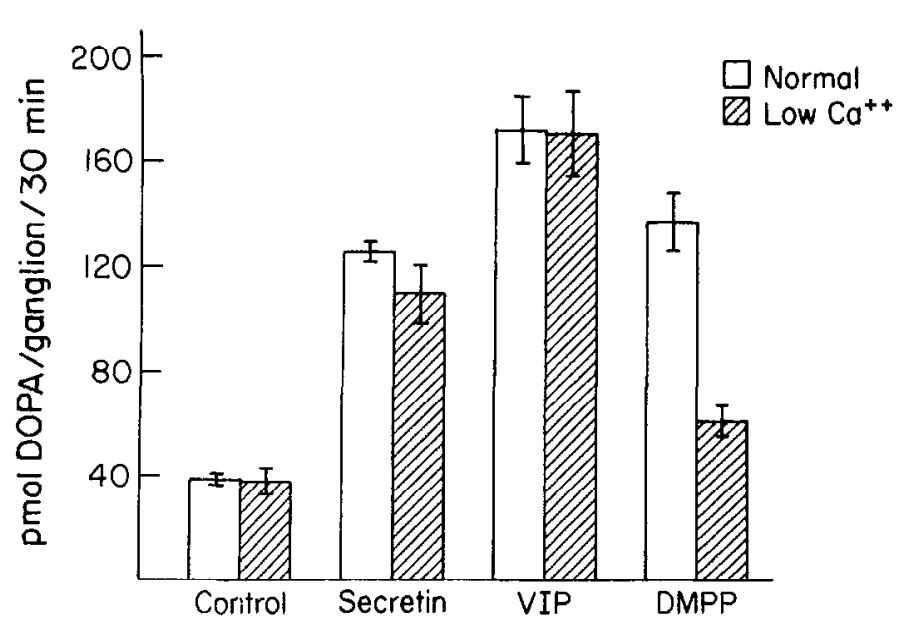

Figure 6. Dependence of the effects of secretin, VIP, and dimethylphenylpiperazinium (OMPP) on the calcium concentration in the incubation medium. Ganglia were preincubated for $30 \mathrm{~min}$ with medium containing a normal concentration of $\mathrm{Ca}^{++}(1.8 \mathrm{~mm})$ and $\mathrm{Mg}^{++}(0.8 \mathrm{~mm})$ or a low concentration of $\mathrm{Ca}^{++}(0.1 \mathrm{~mm})$ and a high concentration of $\mathrm{Mg}^{++}(2.5 \mathrm{mM})$. They were then incubated for $30 \mathrm{~min}$ in similar media to which brocresine and either secretin $(1 \mu \mathrm{M})$. VIP $(10 \mu \mathrm{M})$. DMPP $(100 \mu \mathrm{M})$, or no agonist was added. Each bar represents the mean \pm SEM of three ganglia. The effect of DMPP was reduced by $76 \%$ in the low $\mathrm{Ca}^{++} / \mathrm{high}^{\mathrm{Mg}}{ }^{++}$medium. No significant differences attributable to the ionic composition of the medium were found for the other three groups.

Dose-response curves were determined for the effects of secretin, VIP, and PHI on CAMP levels. Secretin was the most potent of the three peptides followed by VIP (Fig. 1B). VIP produced a significantly higher maximum effect than did secretin. (As in the studies on $\mathrm{TH}$ activity, in these studies on CAMP content the maximum effect of $\mathrm{PHI}$ was not determined due to the extremely high concentrations of peptide which would have been required.) The relationship between the rate of dopa synthesis and the CAMP concentration in individual ganglia exposed to any of the three peptides can be described by a simple hyperbolic function (Fig. 2).

We previously reported that 8-broma-cAMP $(0.5 \mathrm{~mm})$ produced a small increase in TH activity (ip et al., 1983). When the dose-response relationship of this effect was examined, it was found that 8-bromoCAMP at higher concentrations could produce at least a 4 -fold increase in enzyme activity (Fig. 3). Three other purine derivatives tested (i.e., 8-bromoadenosine, 8-bromoadenosine monophosphate, and 8-bromoguanosine $3^{\prime}, 5^{\prime}$-cyclic monophosphate) produced no

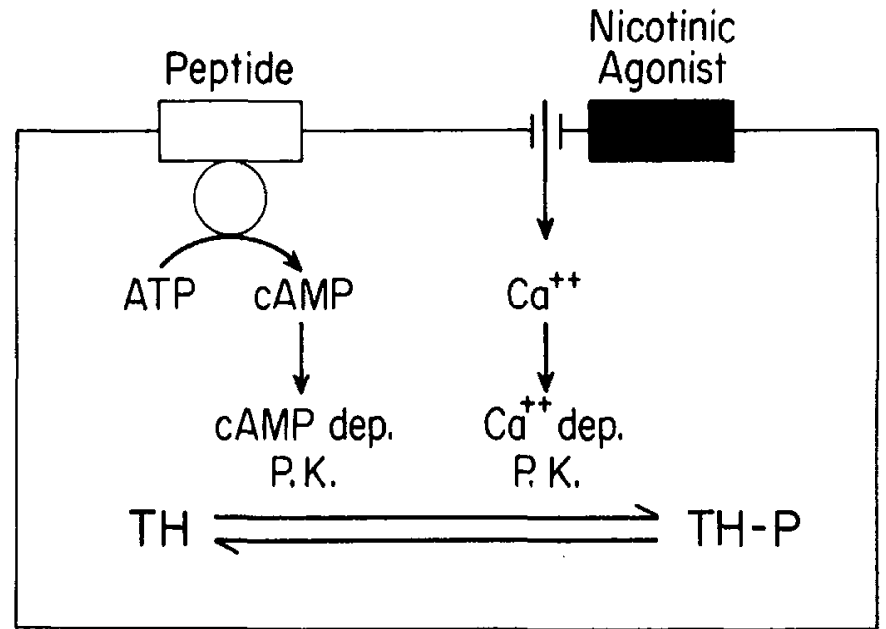

Figure 7. A hypothesis concerning the acute stimulation of TH activity by neuropeptides of the secretin family and by nicotinic agonists. Secretin, VIP, $\mathrm{PH}$, and dimethylphenylpiperazinium (DMPP) all increase $\mathrm{TH}$ activity within minutes of being added to the incubation medium. The increases produced by the three peptides, but not by DMPP, are accompanied by increases in cAMP levels in the ganglia. The increase produced by DMPP. but not those produced by the peptides, is highly dependent on the $\mathrm{Ca}^{++}$concentration in the incubation medium. Since TH has been shown to be a substrate for both a cAMP-dependent and one or more calcium-dependent protein kinases, we have postulated that the former mediates the effects of secretin, VIP, and $\mathrm{PHI}$, and that one of the latter mediates the effects of DMPP on TH activity.

significant effects at a concentration of $10 \mu \mathrm{M}$ (data not shown). On the other hand, forskolin, like 8-bromo-cAMP, increased TH activity (Fig. 4). The $\mathrm{EC}_{50}$ for this effect of forskolin was about $3 \mu \mathrm{M}$, and the maximum increase was approximately 2.5 -fold. The effect of forskolin $(10 \mu \mathrm{M})$ was potentiated by the addition of the phosphodiesterase inhibitor Ro 20-1724 (Table IV). Since cAMP analogues have been shown in certain preparations to release neurotransmitters (Weiner, 1979), the effect of 8-bromo-cAMP on TH activity was examined in previously decentralized ganglia. Cutting the preganglionic cervical sympathetic trunk and allowing time for degeneration of the preganglionic nerve terminals had no significant effect on the increase in TH activity produced by the cyclic nucleotide (Table V). These results indicate that 8 -bromo-cAMP produces this effect via an action on postsynaptic cells in the ganglion rather than by releasing a neurotransmitter from the preganglionic nerve terminals.

Differences in the mechanisms of the nicotinic and peptidergic 
effects. Previous studies have indicated that $\mathrm{TH}$ activity can also be acutely increased by a nicotinic mechanism (Ip et al., 1982b, 1983). Therefore, the effects of the nicotinic agonist dimethylphenylpiperazinium on CAMP levels in the ganglion were examined. The concentration of the agonist used $(100 \mu \mathrm{M})$ was that previously found to produce a maximum elevation in TH activity (lp et al., 1982b). Dimethylphenylpiperazinium produced a 5 -fold increase in $\mathrm{TH}$ activity, whereas no significant effect on CAMP levels was seen (Fig. 5). A second difference between the effects of dimethylphenylpiperazinium, on the one hand, and those of secretin and VIP, on the other hand, was found in their calcium dependence. Lowering the calcium and raising the magnesium concentration in the incubation medium reduced the effect of the nicotinic agonist by $76 \%$ but did not alter the effects of secretin or VIP (Fig. 6).

\section{Discussion}

$\mathrm{TH}$ activity can be increased acutely in a variety of central and peripheral adrenergic neurons. This phenomenon was first described in the vas deforens during clcctrical stimulation of the hypogastric nerve (Weiner et al., 1977). Acute increases in TH activity were subsequently found in a variety of preparations following exposure to depolarizing agents (usually elevated levels of potassium in the medium) or to CAMP analogues (e.g., Goldstein et al., 1976; Chalfie et al., 1979). Furthermore, exposure of homogenates of adrenergic tissues to cAMP-dependent "phosphorylating conditions" was also found to increase enzyme activity (Lovenberg et al., 1975). More recently, it has been shown that $\mathrm{TH}$ purified from PC12 cells is a substrate for a CAMP-dependent protein kinase and that phosphorylation of the enzyme results in enzyme activation (Vulliet et al., 1980). In addition, TH purified from brain has been shown to be a substrate both for a CAMP-dependent protein kinase and for one or more calcium-dependent protein kinases (Joh et al., 1978; Raese et al., 1979; Yamauchi and Fujisawa, 1980). Again, in these studies, phosphorylation of the enzyme was associated with enzyme activation.

Although CAMP appears to be a potential second messenger in the acute regulation of TH activity, the first messenger for such an effect has not been identified. It has been proposed that nerve activity in sympathetic neurons, perhaps via increased entry of calcium ions, leads to an increase in intraneuronal cAMP levels and to phosphorylation and, thereby, activation of $\mathrm{TH}$ (Weiner et al., 1977). However, recent studies on the phosphorylation of TH following potassium depolarization of $\mathrm{PC} 12$ cells suggests that most of the change in phosphorylation is mediated via a CAMP-independent mechanism (Yanagihara et al., 1983). Furthermore, various studies in other preparations have suggested that agents acting via depolarization and agents acting via increasing intracellular CAMP increase TH activity by different mechanisms (Goldstein et al., 1976; Chalfie et al., 1979).

Adenosine has been reported to increase $\mathrm{TH}$ activity in pheochromocytoma cells and in PC12 cells, and this effect appears to be mediated via an increase in cAMP (Emy el al., 1981; Erryy, 1983). However, adenosine does not increase TH activity in guinea pig or bovine adrenal chromaffin cells (Erny, 1983) or in the superior cervical ganglion (Table I). Therefore, the relevance of the finding in adrenal tumor cells to normal tissue remains unclear.

The data presented here suggest that secretin, VIP, and PHI increase TH activity via an increase in cAMP levels (Fig. 7). In confirmation of a previous report (Volle and Patterson, 1982), VIP has been shown to increase CAMP levels in the rat superior cervical ganglion. In addition, we find that two other peptides of the secretin family - secretin and $\mathrm{PHI}$-also produce this effect. The rank orders of potency and efficacy of these three peptides in increasing CAMP levels and TH activity are identical. Furthermore, there appears to be a direct relationship between the activity of TH and the concentration of CAMP in individual ganglia, independent of the peptide to which the ganglia were exposed. This finding is particularly interesting since we have previously presented results that suggest that secretin and VIP act through different receptors in this ganglion (Ip et al., 1982a). Additional evidence for a role of cAMP as a second messenger in this system is the finding that nine other peptides tested, which do not increase TH activity, also do not incrcase cAMP levels. Finally, incubation of ganglia with 8-bromo-cAMP or forskolin (an agent which increases the intracellular concentration of CAMP (Seaman et al., 1981)) produces an increase in $\mathrm{TH}$ activity. One limitation of these experiments is that it is not known whether the changes in cAMP produced by secretin, VIP, and PHI occur in the same cell type in the ganglion as do the changes in TH. Immunohistochemical studies using an antibody directed against CAMP have indicated that changes in this cyclic nucleotide can occur both in principal neurons and in satellite cells in the ganglion depending on the stimulus used (Ariano et al., 1982). In this regard it is interesting to note that isoproterenol, an agonist which does not increase ganglionic $\mathrm{TH}$ activity (Table I) but does increase ganglionic cAMP levels (Quenzer et al., 1979; Briggs et al., 1982), produces the latter change predominantly in satellite cells of the superior cervical ganglion though changes in the principal neurons were also observed (Ariano et al., 1982). It is possible that the increase in cAMP occurring in principal neurons is either too small or does not occur in an appropriate "compartment" of the cell to affect TH activity.

In this study, we have measured the rate of dopa synthesis in whole ganglia; therefore, it is not possible to specify from such measurements whether the changes observed reflect changes in the enzyme TH itself. However, recent results have established that secretin and VIP produce a stable activation of TH activity measured in ganglion homogenates using a subsaturating cofactor concentration and produce a shift in the $\mathrm{pH}$ optimum of the enzyme ( $M$. A. Schwarzschild and R. E. Zigmond, unpublished observations). Horowitz and Perlman (1984) reported that nicotinic and muscarinic agonists and 8-bromo-cAMP also produce a stable activation of the enzyme. Thus, the increased rates of tyrosine hydroxylation in intact ganglia reported both in the present study and in earlier studies (Ip et al., 1982a, b) are likely to result from changes in the properties of the enzyme itself rather than from changes in the levels of substrates, cofactor, or inhibitors.

In addition to the CAMP-dependent mechanism of regulating ganglionic TH activity, there is also a cAMP-independent mechanism. Evidence for this comes from our finding and that of other workers (Volle et al., 1982) that dimethylphenyipiperazinium does not increase CAMP levels in the superior cervical ganglion. Dimethylphenylpiperazinium has been shown to increase calcium uptake by cells in the ganglion (Volle et al., 1981), and the increase in TH activity it produces is highly dependent on the calcium concentration of the incubation medium (Fig. 6). Thus, the regulation of TH activity by nicotinic agonists may occur via a calcium-dependent protein kinase (Fig. 7). Such a mechanism may also underlie the increase in $\mathrm{TH}$ activity seen in decentralized ganglia incubated in a medium containing an elevated concentration of potassium (Ip et al., 1983).

Although our data make it likely that secretin, VIP, and PHI produce their effects on TH activity via an increase in CAMP, and presumably via CAMP-dependent phosphorylation of the enzyme (Fig. 7), they do not establish whether and under what conditions such regulation occurs in vivo. Previous studies have indicated that stimulation of the preganglionic cervical sympathetic nerve at $10 \mathrm{~Hz}$ for $30 \mathrm{~min}$ leads to a 4-fold increase in $\mathrm{TH}$ activity and that approximately half of this effect is mediated by a noncholinergic transmitter (Ip et al., 1983). A small number of nerve processes containing VIP-like immunoreactivity has been found in the rat superior cervical ganglion by immunohistochemical techniques (Hokfelt et al., 1977), and VIPlike immunoreactivity has been detected in ganglion homogenates by radioimmunoassay (M. C. Beinfeld, N. Y. Ip, and R. E. Zigmond, unpublished observations). However, it is not known whether this material is in preganglionic nerve terminals and whether it is released during stimulation of the cervical sympathetic trunk. Furthermore, data on the presence of secretin-like or PH-like immunoreactivity in this ganglion have not been reported, although both immunoreactiv- 
ities have been detected in the central nervous system (e.g., O'Donohue et al., 1981; Christofides et al., 1982). Thus, it is not possible at present to conclude whether or not the noncholinergic effect of nerve stimulation is mediated by one of these peptides. It is of considerable interest, however, to note that preganglionic nerve stimulation has been shown to increase CAMP levels in the ganglion via a noncholinergic mechanism (Briggs et al., 1982; Volle et al., 1982) and that at least part of this increase occurs in principal neurons in the ganglion (Ariano et al., 1982). Thus, whatever the identity of the noncholinergic transmitter(s) in the rat superior cervical ganglion, it is plausible that at least part of its effect on TH activity is mediated via an increase in cAMP levels.

The findings that secretin, VIP, and PHI increase cAMP levels in sympathetic ganglia raise the possibility that these peptides alter other aspects of synaptic chemistry in addition lo increasing $\mathrm{TH}$ activity. CAMP-dependent protein phosphorylation has been shown to be involved in the regulation of other proteins in nervous tissue (e.g., Nestler and Greengard, 1983) and has been implicated in the control of aspects of synaptic function other than transmitter synthesis (e.g., Kandel and Schwartz, 1983). Thus, these peplides may well produce multiple effects on sympathetic neurons via changes in cAMP levels.

Our studies have been restricted to the superior cervical ganglion; thus, the effects we measure on TH activity probably occur predominaritly in the cell bodies or dendrites of principal neurons and perhaps aiso in the much smaller population of small intensely fluorescent (SIF) cells. Although it has been proposed that some recurrent axon collaterals of principal neurons exist, the number of adrenergic nerve terminals in the ganglion, if any, is probably small. However, the existence of peptide receptors in the ganglion raises the question of whether similar receptors might occur on adrenergic nerve terminals. This question is of particular interest since, in certain instances, postganglionic parasympathetic neurons are known to release VIP (Lundberg, 1981) and since sympathetic and parasympathetic nerve terminals in many autonomic effector organs are probably in close proximity. Thus, one can imagine a heteroneuronal interaction occurring, involving the regulation of transmitter synthesis in one neuron by a substance released by nearby neurons.

\section{References}

Amiranoff, B., and G. Rosselin (1982) VIP receptors and control of cyclic AMP production. In Vasoactive Intestinal Peptide, S. 1. Said, ed., pp. 307322, Raven Press, New York.

Ariano, M. A., C. A. Briggs, and D. A. McAfee (1982) Cellular localization of cyclic nucleotide changes in rat superior cervical ganglion. Cell. Mol. Neurobiol. 2: 143-156.

Briggs, C. A., G. J. Whiting, M. A. Ariano, and D. A. McAfee (1982) Cyclic nucleotide metabolism in the sympathetic ganglion. Coll. Mol. Nourobiol. 2: $129-141$.

Brown, B. L., J. D. M. Albano, R. P. Ekins, and A. M. Sgherzi (1971) A simple and sensitive saturation assay method for the rreasurement of adenosine $3^{\prime}: 5^{\prime}$-cyclic monophosphate. Biochem. J. 121: 561-562.

Chalazonitis, A., and R. E. Zigmond (1980) Effects of synaptic and antidromic stimulation on tyrosine hydroxylase activity in the rat superior cervical ganglion. J. Physiol. (Lond.) 300: 525-538.

Chalazonitis, A. P. J. Rice, and R. E. Zigmond (1980) Increased ganglionic tyrosine hydroxylase and dopamine- $\beta$-hydroxylase activities following preganglionic nerve stimulation: Role of nicotinic receptors. J. Pharmacol. Exp. Ther. 213: 139-143

Chalfie, M., L. Settipani, and R. L. Perlman (1979) The role of cyclic adenosine $3^{\prime}: 5^{\prime}$-monophosphate in the regulation of tyrosine 3-monooxygenase activity. Mol. Pharmacol. 15: 263-270.

Christofides, N. D., Y. Yiangou, G. P. McGregregor, E. Aarons, P. L. Woodhams, K. Tatemoto, and S. R. Bloom (1982) Distribution of PHI in the rat brain. Biomed. Res. 3: 573-574.

Dun, N. J., and Z. G. Jiang (1982) Non-cholinergic excitatory transmission in inferior mesenteric ganglia of the guinea-pig: Possible mediation by substance P. J. Physiol. (Lond.) 325: 145-159.

Erny, R. E. (1983) Regulation of adenylate cyclase and catecholamine synthesis by adenosine in pheochromocytoma cells. Ph.D. thesis, Harvard University, Cambridge, MA.
Erny, R. E., M. W. Berezo, and R. L. Perlman (1981) Activation of tyrosine 3monooxygenase in pheochromocytoma cells by adenosine. J. Biol. Chem. 256: $1335-1339$.

Gardner, J. D., and R. T. Jensen (1981) Regulation of pancreatic enzyme secretion in vitro. In Physiology of the Gastrointestinal Tract, L. R. Johnson, ed., pp. 831-871, Raven Press, New York.

Goldstein, M. R. L. Bronaugh, B. Ebstein, and C. Roberge (1976) Stimulation of tyrosine hydroxylase activity by cyclic AMP in synaptosomes and in soluble striatal enzyme preparations. Brain Res. 109: 563-574.

Hokfelt, T., L. -G. Elivin, M. Schultzberg, K. Fuxe, S. I. Said, V. Mutt, and M. Goldstein (1977) Immunohistochemical evidence of vasuactive intestinal polypeptide-containing neurons and nerve fibers in sympathetic ganglia. Neuroscience 2: 885-896.

Horowitz, J., and R. L. Periman (1984) Activation of tyrosine hydroxylase in the superior cervical ganglion by nicotinic and muscarinic agonists. J. Neurochem. 43: 546-552.

Ip, N. Y., and R. E. Zigmond (1983) Acute regulation of ganglionic tyrosine hydroxylase activity by secretin, vasoactive intestinal peptide and $\mathrm{PHI}$. Soc. Neurosci. Abstr. 9: 19.

ip, N. Y., C. K. Ho, and R. E. Zigmond (1982a) Secretin and vasoactive intestinal peptide acutely increase tyrosine 3-monooxygenase activity in the rat superior cervical ganglion. Proc. Natl. Acad. Sci. U. S. A. 79: 75667569 .

Ip, N. Y., R. L. Periman, and R. E. Zigmond (1982b) Both nicotinic and muscarinic agonists acutely increase tyrosine 3-monooxygenase activity in the superior cervical ganglion. J. Pharmacol. Exp. Ther. 223: 280-283.

Ip, N. Y., R. L. Perlman, and R. E. Zigmond (1983) Acute transsynaptic regulation of tyrosine 3-monooxygenase activity in the superior cervical ganglion: Evidence for both cholinergic and noncholinergic mechanisms. Proc. Natl. Acad. Sci. U. S. A. 80: 2081-2085.

Ip, N. Y., C. Baldwin, and R. E. Zigmond (1984) Acute stimulation of ganglionic tyrosine hydroxylase activity by secretin, VIP and PHI. Peptides 5: 309-312.

Jan, L. $Y_{\text {, }}$ and Jan, $Y$. N. (1982) Peptidergic transmission in sympathetic ganglia of the frog. J. Physiol. 327: 219-246.

Joh, J. H., D. H. Park, and D. J. Reis (1978) Direct phosphorylation of brain tyrosine hydroxylase by cyclic AMP-dependent protein kinase: Mechanism of enzyme activation. Proc. Natl. Acad. Sci. U. S. A. 75: 4744-4748.

Kandel, E. R, and J. H. Schwartz (1983) Molecular biology of learning: Modulation of transmitter release. Science 218: 433-443.

Krieger, D. T., M. J. Brownstein, and J. B. Martin (1983) Brain Peptides, John Wiley \& Sons, Inc., New York.

Lovenberg, W., E. A. Bruckwick, and I. Hanbauer (1975) ATP, cyclic AMP, and magnesium incrcase the affinity of rat striatal tyrosine hydroxylase for its cofactor. Proc. Natl. Acad. Sci. U. S. A. 72: 2955-2958.

Lundberg, J. M. (1981) Evidence for coexistence of vasoactive intestinal peptide (VIP) and acetylcholine in neuroris of cal exocrine glands. Murphological, biochemical and functional studies. Acta Physiol. Scand. Suppl. 496: 1-57.

Nestler, E. J., and P. Greengard (1983) Protein phosphorylation in the brain. Nature 305: 583-588.

O'Donohue, T. L., C. G. Charlton, R. L. Miller, G. Boden, and D. M. Jacobowitz (1981) Identification, characterization, and distribution of secretin immunoreactivity in rat and pig brain. Proc. Natl. Acad. Sci. U. S. A. 78: 52215224.

Quenzer, K., D. Yahn, K. Alkadhi, and R. L. Volle (1979) Transmission blockade and stimulation of ganglionic adenylate cyclase by catecholamines. J. Pharmacol. Exp. Ther. 208: 31-36.

Raese, J. D. A. M. Aidelman, J. Makk, E. A. Bruckwick, W. Lovenberg, and J. D. Barchas (1979) Brain striatal tyrosine hydroxylase: Activation of the enzyme by cyclic AMP-independent phosphorylation. Commun. Psychopharmacol. 3: 295-301.

Seaman, K. B., W. Padgett and J. W. Daly (1981) Forskolin: Unique diterpene activator of adenylate cyclase in membranes and in intact cells. Proc. Natl. Acad. Sci. U. S. A. 78: 3363-3367.

Tsunoo, A., S. Konishi, and M. Otsuka (1982) Substance P as an excitatory transmitter of primary afferent neurons in guinea-pig sympathetic ganglia. Neuroscience 7: 2025-2037.

Volle, R. L., and B. A. Patterson (1982) Regulation of cyclic AMP accumulation in a rat sympathetic ganglion: Effects of vasoactive intestinal polypeptide. J. Neurochem. 39: 1195-1197.

volle, R. L. , L. F. Quenzer, B. A. Patterson, K. A. Alkadhi, and E. G. Henderson (1981) Cyclic guanosine $3^{\prime}: 5^{\prime}$-monophosphate accumulation and ${ }^{45} \mathrm{Ca}$ uptake by rat superior cervical ganglia during preganglionic stimulation. J. Pharmacol. Exp. Ther. 219: 338-343. 
Volle, R. L., L. F. Quenzer, and B. A. Patterson (1982) The regulation of cyclic nucleotides in a sympathetic ganglion. J. Auton. Nerv. Syst. 6: 6572.

Vulliet, P. R., T. A. Langon, and N. Weiner (1980) Tyrosine hydroxylase: A substrate of cyclic AMP.dependent protein kinase. Proc. Natl. Acad. Sci. U. S. A. 77: 92-96.

Weiner, N. (1979) Multiple factors regulating the release of norepinephrine consequent to nerve stimulation. Fed. Proc. 38: 2193-2202.

Weiner, N., F. -L. Lee, E. Brenes, E. Dreyer (1977) Enzymology of tyrosine hydroxylase and the role of cyclic nucleotides in its regulation. In Structure and Function of Monoamine Enzymes, E. Usdin, N. Weiner, and M. B. H. Youdim, eds., pp. 109-148, Marcel Dekker, New York.

Yamauchi, T., and F. Fujisawa (1980) Involvement of calmodulin in the $\mathrm{Ca}^{2+}$. dependent activation of rat brainstem tyrosine 3-monooxygenase. Bio chem. Int. 1: 98-104.

Yanagihara, N., A. W. Tank, T. A. Langan, and N. Weiner (1983) Enhanced phosphorylation of tyrosine hydroxylase at more than one site is induced by $56 \mathrm{mM} \mathrm{K}^{+}$in rat pheochromocytoma PC.12 cells in culture. Soc. Neurosci. Abstr. 9: 1125.

Zigmond, R. E. (1980) The long-term regulation of ganglionic tyrosine hy. droxylase by preganglionic nerve activity. Fed. Proc. 39: 3003-3008

Zigmond, R. E., and Y. Ben-Ari (1977) Electrical stimulation of preganglionic nerve increases tyrosine hydroxylase activity in sympathetic ganglia. Proc. Natl. Acad. Sci. U. S. A. 74: 3078-3080.

Zigmond, R. E., C. Baldwin, and N. Y. Ip (1983) Evidence for the involvement of cyclic AMP in the acute stimulation of ganglionic tyrosine hydroxylase activity produced by certain neuropeptides. Soc. Neurosci. Abstr. 9. 19. 